Brazilian Journal

of Chemical

ISSN 0104-6632

Printed in Brazil

Engineering

www.scielo.br/bjce

Vol. 35, No. 02, pp. 403 - 414, April - June, 2018

dx.doi.org/10.1590/0104-6632.20180352s20160329

(cc) BY

\title{
SIMULATION AND EXPERIMENTAL STUDY OF METHANE-PROPANE HYDRATE DISSOCIATION BY HIGH PRESSURE DIFFERENTIAL SCANNING CALORIMETRY
}

\author{
Davi Éber Sanches de Menezes ${ }^{1}$, Thiago Waldowski Ralhaํ․ Luís \\ Fernando Mercier Franco ${ }^{1,2}$, Pedro de Alcântara Pessôa Filho ${ }^{1}$ and \\ Maria Dolores Robustillo Fuentes ${ }^{1 *}$ \\ ${ }^{1}$ Department of Chemical Engineering, Engineering School, University of São Paulo, \\ 05424-970, São Paulo - SP, Brazil. \\ ${ }^{2}$ School of Chemical Engineering, State University of Campinas, 13083-852, \\ Campinas - SP, Brazil.
}

(Submitted: May 17, 2016; Revised: May 04, 2017; Accepted: May 15, 2017)

\begin{abstract}
Binary and ternary systems composed of methane-water and methane-propane-water, respectively, were studied using high pressure differential scanning calorimetry. The methodology was validated by comparing results for the binary system to experimental data obtained in the literature. The hydrate dissociation temperatures for the ternary system (methane-propane-water) at $21 \mathrm{MPa}$ were experimentally determined for different compositions of the gas mixture and mole fractions of propane higher than 0.1 in the ternary system. Our results are in good agreement with the values predicted by applying the Cubic Plus Association (CPA) equation of state coupled with van der Waals-Platteeuw model for the hydrate phase. Although experimental results are considered satisfactory for both binary and ternary systems, higher deviations between our values and the simulated ones for the ternary system, considering peak temperature instead of the extrapolated onset as the hydrate dissociation temperature, are believed to be a consequence of dynamic effects that promote the formation of a heterogeneous hydrate and are negligible for the binary system.
\end{abstract}

Keywords: methane, propane, hydrates, high pressure calorimetry, simulation.

\section{INTRODUCTION}

The study of gas hydrate formation and dissociation has great importance in the petrochemical industry to define operational conditions that ensure the flow of oil and gas in pipelines (Sloan et al., 2011). Furthermore, gas hydrates are considered to be a potential alternative energy source (Sloan and Koh,
2008; Allison and Boswell, 2007). The understanding of the thermodynamic and kinetic behavior of gas hydrates also allows their use in other applications, such as in water purification and carbon capture and storage (Linjun et al., 2013; Vorotyntsev and Malyshev, 2011).

Gas hydrates are formed at high pressures and low temperatures. These thermodynamic conditions

*Corresponding author: Maria Dolores Robustillo Fuentes E-mail address: mrobustillof@gmail.com

This is an extended version of the manuscript presented at the VIII Brazilian Congress of Applied Thermodynamics - CBTermo 2015, Aracaju, Brazil. 
can be found in continental slopes, polar regions and deep water environments (Makogan, 1981; Kvenvolden and Rogers, 2005). The delineation of hydrate chemical equilibrium also depends on the composition of the system that generated it, which may consist of liquid water (often saturated with hydrocarbons), a gas hydrocarbon phase (often saturated with water) and a liquid hydrocarbon phase, for example.

Hydrate crystalline structures are composed of water molecules associated by hydrogen bonds that form a host lattice. The cavities within the network are called host cages and lodge small molecules, such as hydrocarbons. So far, the most common structural families of gas hydrates found in nature are: the cubic structure I (S1), cubic II (S2) and the structure H. The size of the guest molecule determines the type of structure to be formed, e.g., methane tends to form structure I, while propane tends to form structure II. Therefore, the composition of the gas mixture can influence the thermodynamic equilibrium of the hydrate (Sloan and Koh, 2008). Lee et al. (2005) studied hydrates formed from gas mixtures (methane with ethane or propane) and water droplets and concluded that the composition of the gaseous phase also affects gas hydrates morphology and crystal growth.

Dissociation heat $\left(\Delta \mathrm{H}_{\text {diss }}\right)$ and dissociation temperature are physical properties often used in the development of thermodynamic models involving hydrate phase equilibrium (Kim et al., 1987; Ullerichet al., 1987; Selim and Sloan, 1989). Both properties can be determined accurately by calorimetry (Deschamps and Dalmazzone, 2009; Gupta etal., 2008). The results, found in the literature for gas hydrates at high pressures are, however, generally scarce and obtained by extrapolation or less accurate and more laborious techniques such as visual observation in PVT cells (Setzmann and Wagner, 1991; Ruffine et al., 2010; Xiang et al., 2013).

Many studies in the literature investigate systems based on oil samples (Chen et al., 2012, Dalmazzone et al., 2009; Ivanova et al., 2015; Semenov et al., 2015). Nevertheless, the analysis of phase equilibria of hydrates formed from water and free gas is primal to understand these structures. Moreover, simpler systems can facilitate the reproducibility of laboratory experiments and the study of other effects on the formation of hydrates, such as the presence of inhibitors.
Therefore, the aim of this paper is to present new data for dissociation temperatures of methane and propane hydrates formed from liquid water and gases in the supercritical state, employing a methodology based on high-pressure differential scanning calorimetry. Recent studies indicate the applicability of high pressure differential scanning calorimetry to determine the hydrate phase equilibrium (Cha et al., 2016; Chu et al., 2016; Sabil et al., 2015). The energy transitions coming from phase changes or rearrangements of the crystalline structure of the material, for example, show endothermic or exothermic peaks depending on the characteristic of the transition. The ice melting and the dissociation of hydrates are endothermic processes and can be observed during heating of the sample. The system composition influences the equilibrium conditions of hydrates and such an influence is also thoroughly considered in this work.

\section{MATERIALS AND METHODS}

\section{Reagents}

Milli-Q water was used in all experiments. Methane gas $(99.5 \%)$ and propane $(99.5 \%)$ were provided by the companies White Martins and Gama Gases, respectively.

\section{Equipment}

The apparatus used in this work was a high pressure micro calorimeter ( $\mu$-DSC7 evo - Setaram), calibrated from the factory with naphthalene (Setaram standard, purity $\geq 99.97 \%$ ) by performing a Joule Effect calibration. A temperature correction coefficient was also generated in our laboratory based on known melting temperatures of certain standards provided by Sigma Aldrich (n-decane $(\geq 99 \%)$, cyclohexane $(\geq 99.9 \%)$, dodecane $(\geq 99 \%)$, hexadecane ( $\geq 99 \%)$ and eicosane $(\geq 99 \%)$ to obtain more accurate results at lower temperatures and using a heating rate of $1 \mathrm{~K} / \mathrm{min}$. The instrument has two high pressure cells (reference and sample) made of incoloy and inserted into an oven capable of reaching temperatures from $228.15 \mathrm{~K}$ (aided by an external cooler Julabo F32) to $393.15 \mathrm{~K}$. A high-pressure panel (PMHP 1000 Setaram-V2) and a gas mixer (Gas Panel 200 bar 2723 Top Industrie) were incorporated into the micro calorimeter. This configuration allows operation with a gas mixture under constant pressure or constant volume up to 1000 bar, depending on the application (Figure 1). 


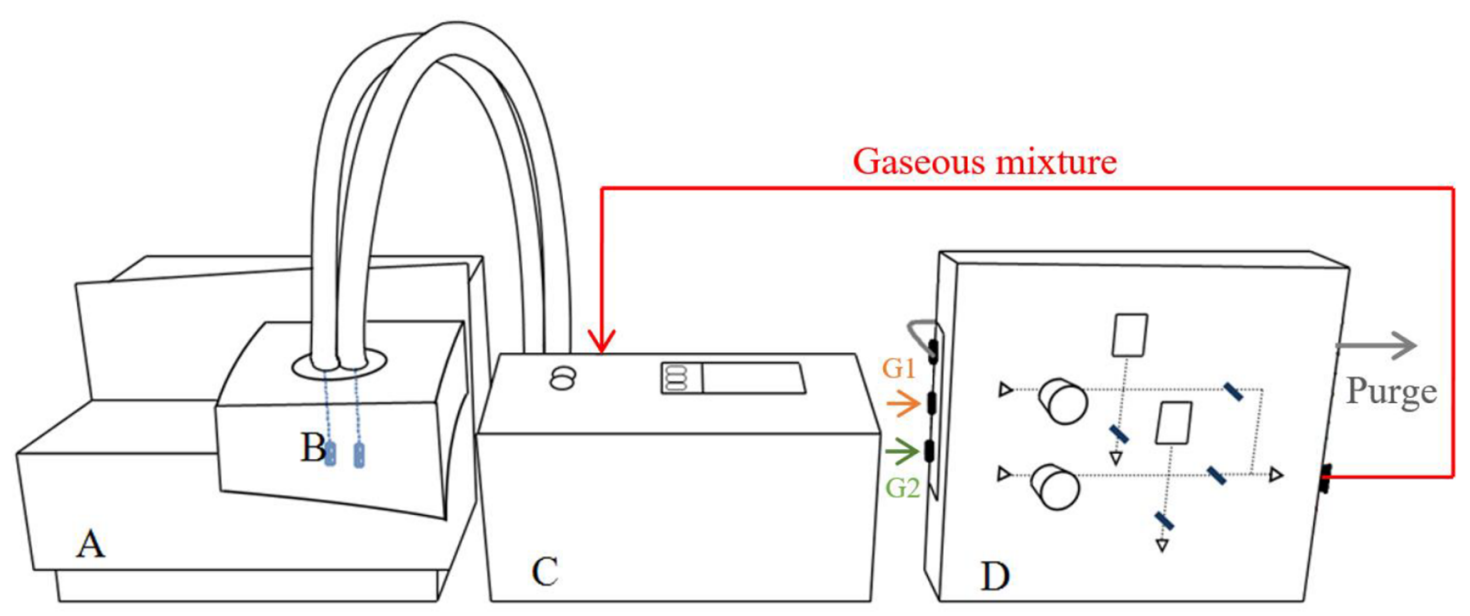

Figure 1. Experimental setup: A) High pressure $\mu \mathrm{DSC}$; B) High pressure cells; C) Gas Panel of Compression; D) Gas Mixer.

\section{Estimation of System Composition}

The overall composition of the system was calculated from the amount of water in the cell and the gas pressure. In the case of experiments with both gases (methane and propane), a mixer was used. It was operated according to the following equation:

$$
\Delta P=P_{1} \cdot \frac{x_{2}}{x_{1}}
$$

$\Delta P$ is the pressure difference between the gases and it is related to the partial pressure of the gas injected after the lowest pressure gas. $P_{I}$ is the pressure of the lowest pressure gas and $x_{1}$ and $x_{2}$ are the mole fractions of lowest and highest pressure gas, respectively.

It is not possible to determine gravimetrically the exact amount of gas inside the cell to determine the global composition. Thus, the total amount of gas was estimated by considering the initial conditions of temperature and pressure $(343.15 \mathrm{~K}$ and $21 \mathrm{MPa})$ and the cell volume $(0.19 \mathrm{~mL})$ using the Peng-Robinson equation of state (EoS). The reliability of this equation was studied by comparing density results with data presented in the literature (Sage et al., 1934; NIST (National Institute of Standards and Technology)). For mixtures of methane and propane, van der Waals mixing rules were used, with a binary interaction parameter, $K_{i j}$, equal to 0.012 (Gao, 1992).

Such a method of estimating the composition, as the one described above, has intrinsic limitations. The volume of the cells is known but the system is not completely closed. The valves are placed in the gas panel that is connected to the cells through two thin tubes, as shown in Figure 1. Although these tubes are insulated, one can admit heat loss in the way. As temperature changes inside the cell, there could be a deviation in the gas phase density due to expansion to the coolest region. Despite the absence of stirring, it is considered to be a homogeneous gas phase mixture, since methane (higher pressure gas) is injected progressively after propane (lower pressure gas) in the gas panel.

\section{Experimental Procedure}

All analyses were carried out using the highpressure micro differential scanning calorimeter (HP- $\mu \mathrm{DSC}$ ) at $21 \mathrm{MPa}$ with accuracy of $\pm 0.2 \mathrm{MPa}$. The reference cell was kept empty and the calculated amount of water was added in the sample cell. The subsequent thermal cycle is described below:

I Heating the DSC oven to $343.15 \mathrm{~K}$ followed by a 10-min equilibration time at this temperature;

II Gas injection and compression up to the established pressure $P$, followed by a 10 -min equilibration time at this condition;

III Cooling down to $228.15 \mathrm{~K}$ at $1 \mathrm{~K} / \mathrm{min}$, followed by a 10 -min equilibration time at this temperature;

IV Heating up to $343.15 \mathrm{~K}$ at $1 \mathrm{~K} / \mathrm{min}$.

As no stirring is present in the system, hydrate nucleation is limited by the mass transfer process, and sub-cooling is necessary to obtain the crystallization (Daraboina et al., 2013). Therefore, the cooling zone was extended down to $228.15 \mathrm{~K}$. Figure 2 presents the procedure used in all experiments. The first thermogram (A) exhibits the temperature profile, whereas the second one (B) indicates the difference in the heat flow between reference and sample cells. The experimental dissociation temperature can be obtained from both the extrapolated onset temperature or the peak of the curve related to hydrate dissociation, as indicated in Figure 2. In fact, there is no agreement that clearly 
defines the melting or dissociation temperature on the calorimetric signal (Kouakou et al. 2013). Although it is known that the onset temperature represents the beginning of the thermal event and it should be less influenced by heating rate or sample mass variations than peak temperature - which corresponds to complete melting in organic compounds -, the onset temperature can be very difficult to locate when other transitions, which can be ascribed to kinetic and dynamic effects, lattice irregularities provoked by empty cavities, polymorphism or simple noise, are extremely close and overlapped peaks are observed. For that reason, depending on the substance or the studied system the use of the peak temperature could be preferred.

\section{Modeling}

The experimental results were compared with data obtained by simulations using Multiflash 6.0 (Infochem Computer Services). The program applies the CPA equation of state (Cubic Plus Association) for the liquid and vapor phases (Santos et al., 2015) and the model of Van der Waals and Platteeuw (1959) for the chemical potential of the hydrate phase $\left(\mu_{\omega}^{H}\right)$ (Equation 2).

$$
\frac{\mu_{\omega}^{H}}{R T}=\frac{g_{\omega}^{\beta}}{R T}+\sum_{m}^{\text {cages }} U_{m} \ln \left(1-\sum_{j}^{\text {guests }} \theta_{j m}\right)
$$

where $v_{m}$ is the number of cages of type $m$ per water molecule in the structure unit cell and $\theta_{j m}$ is related to the occupancy of guest $j$ in the hydrate cage. The term $g_{\omega}^{\beta}$ represents the free energy of empty hydrates.

\section{RESULTS AND DISCUSSION}

\section{Methane Density}

The Peng-Robinson EoS was used to determine the mass of gas and hence the composition of the system, considering the pressure and temperature at the moment the gas was injected and the free volume inside the cell (volume occupied by water subtracted from total volume). To verify the validity of the Peng-Robinson EoS, comparison of the gas density using this equation was made with data obtained in the literature. For the experiments conducted only with water and methane, literature data for methane density were taken from the NIST database. As shown in Figure 3, for temperatures higher than $250 \mathrm{~K}$, Peng-Robinson EoS is a reliable model to calculate the density of methane at $21 \mathrm{MPa}$. The performance of the PR-EoS improves as the temperature increases. As the gas was injected into the cell at $343.15 \mathrm{~K}$, the estimated error at that temperature is $2.5 \%$, which was considered reasonable for applying this equation to calculate the mass of gas inside the cell.

\section{Methane-propane mixture density}

For mixtures of methane and propane, the gaseous mixture density estimated using the PengRobinson EoS was compared with the experimental data published by Sage et al. (1934), who measured the density of mixtures at various pressures (from atmospheric to $20 \mathrm{MPa}$ ), temperatures (from 293.15 $\mathrm{K}$ to $363.15 \mathrm{~K}$ ) and compositions (from pure methane
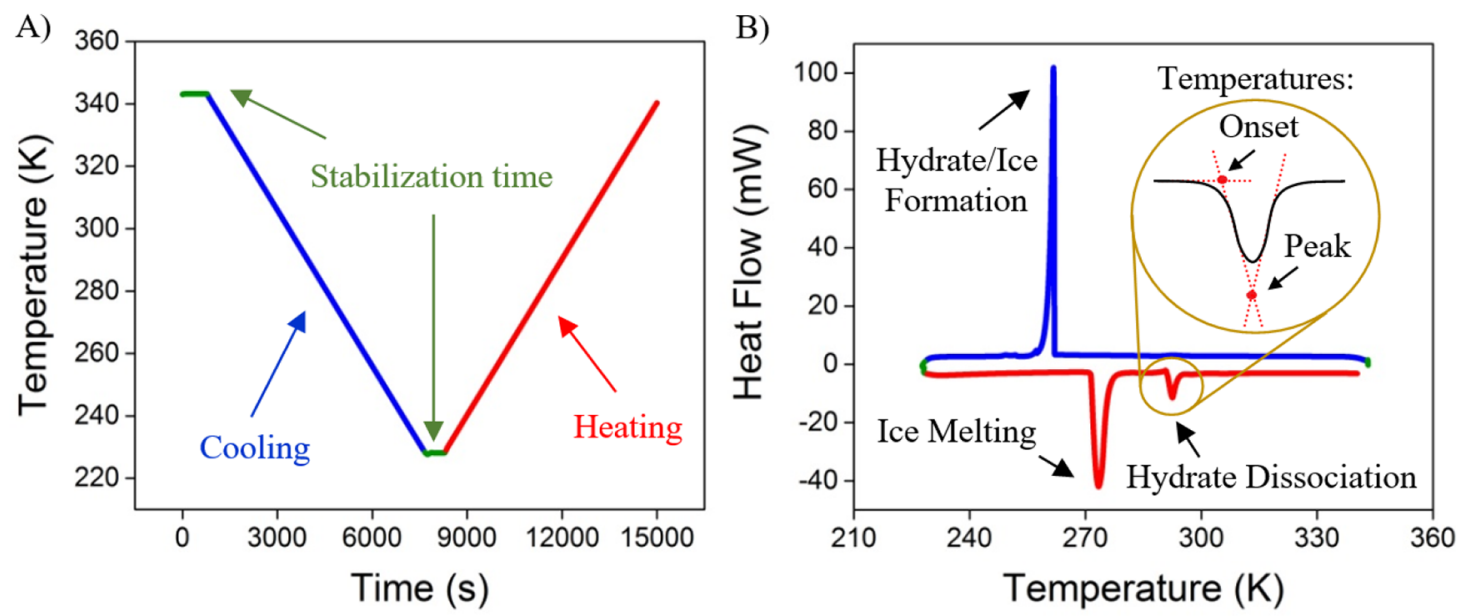

Figure 2. Procedure designed to study the hydrate dissociation temperature based on HP- $\mu$ DSC: A) Thermal profile of all analyses; B) Typical peaks obtained from the analysis at $21 \mathrm{MPa}$. 
to pure propane). Figure 4 shows the density as a function of pressure and methane mole fraction at 343.15 K. Figure 4A presents the literature data, Figure 4B presents the results from the Peng-Robinson EoS, and Figure 4C shows the deviation between them. The Peng-Robinson EoS provides density values slightly larger than experimental ones, but this deviation is lower at higher pressures (absolute value lower than $5 \%$ at $20 \mathrm{MPa}$ ). The hydrate dissociation temperature remains practically unaffected by deviations of this order of magnitude. Hence, this equation seems suitable to calculate the amount of gas inside the cell.
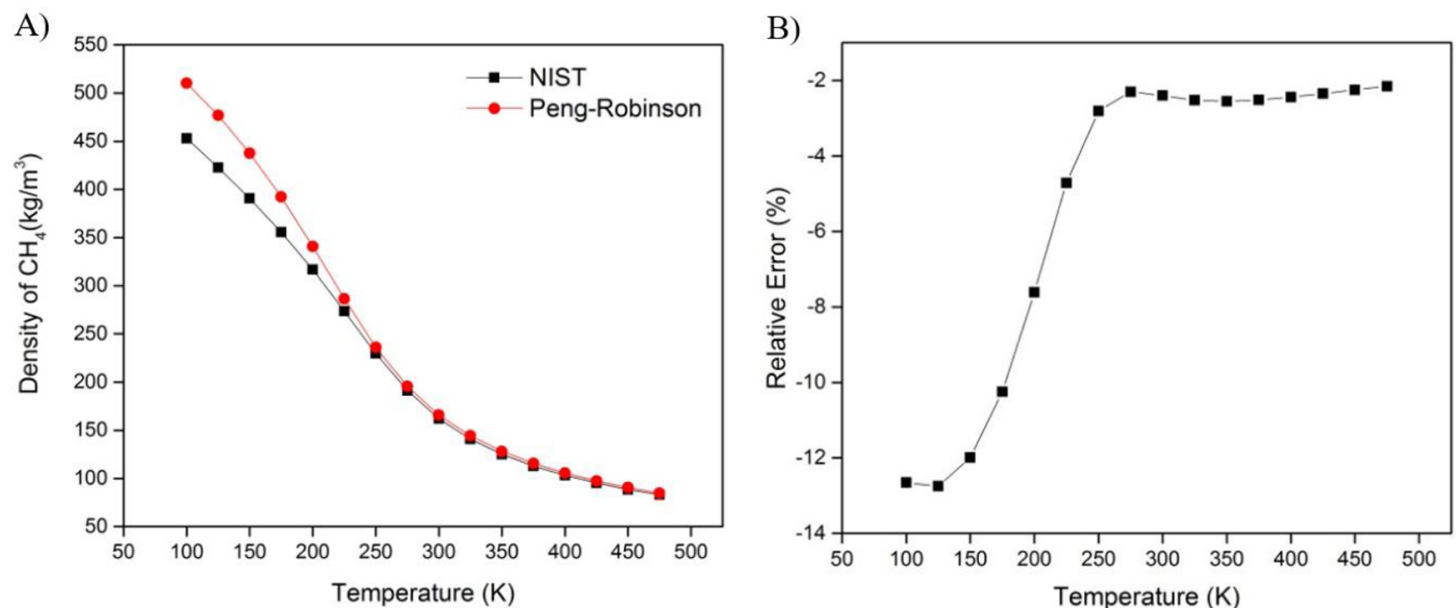

Figure 3. Methane density as a function of temperature at $21 \mathrm{MPa}$ : A) Red continuous line, Peng-Robinson EoS calculations. Black continuous line, NIST data; B) Relative error between Peng-Robinson EoS and NIST data.

A)

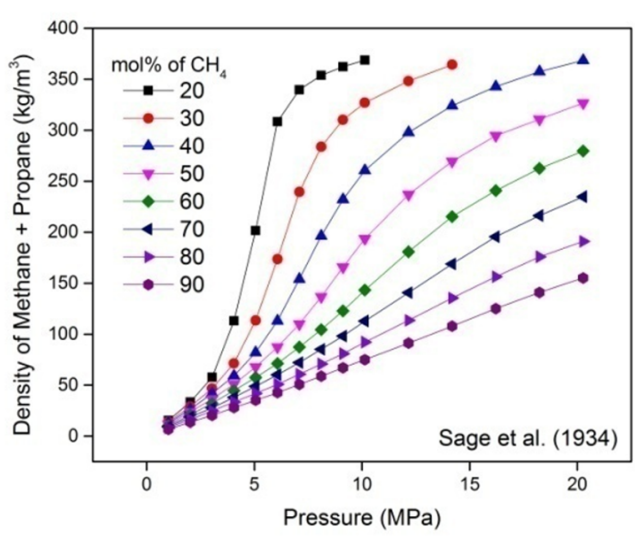

B)

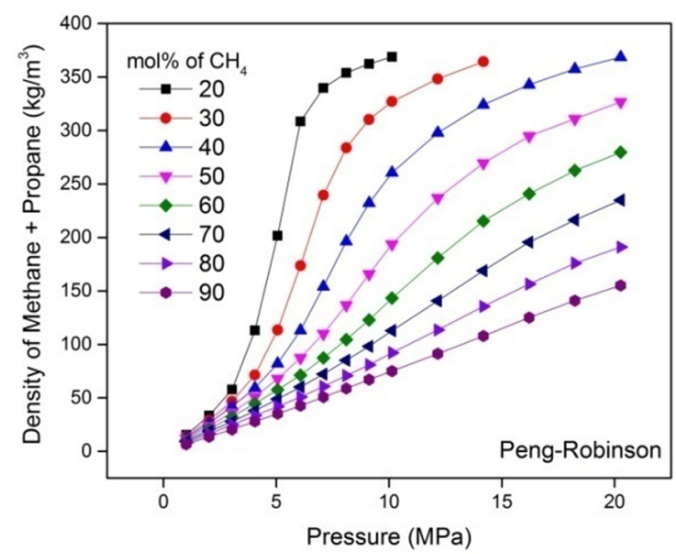

C)

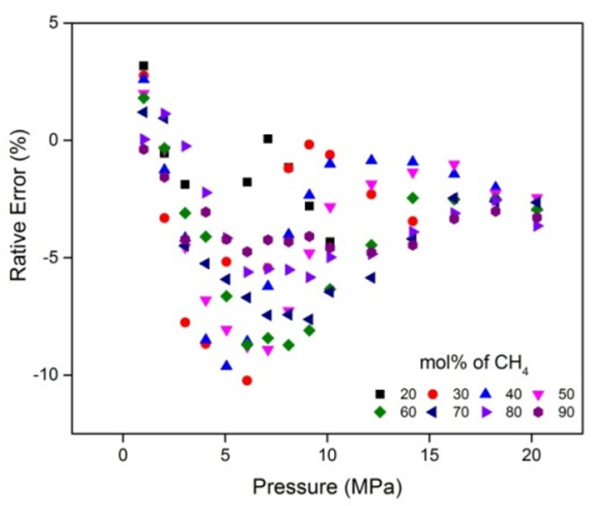

Figure 4. Methane+propane densities at $343.15 \mathrm{~K}$ as a function of pressure and methane mole fraction. A) Experimental data obtained by Sage et al. (1934); B) Results from the Peng-Robinson EoS. C) Relative error between the results from the Peng-Robinson EoS and the experimental data obtained by Sage et al. (1934). 


\section{Methane-water System}

The system composed of water and methane was studied mainly to validate the methodology described above with other experimental works comparing the hydrate dissociation temperature. Table 1 compares experimental results to simulations from Multiflash 6.0 (Infochem Computer Services), and shows the absolute deviation between experimental and calculated values and some data reported in the literature. The highest absolute deviation was obtained for the onset value of the mixture formed by 0.82 mole fraction of methane $(-1.44 \mathrm{~K})$. Figure 5 shows heating thermograms of the binary system, in which the ice melting and methane hydrate dissociation processes at $21 \mathrm{MPa}$ and at different ratios of methane and water are observed at lower and higher temperatures, respectively. For the 0.82 mole fraction of methane overlapped peaks are observed that, as previously mentioned, can be ascribed to kinetic and dynamic effects, lattice irregularities provoked by empty cavities, polymorphism or simple noise, which may influence the onset temperature value.

The value of root-mean square deviation (RMSD) was also obtained through the following equation:

$$
R M S D=\left(\frac{\sum_{i}\left(T_{i}^{S I M}-T_{i}^{E X P}\right)^{2}}{N}\right)^{0.5}
$$

Predicted values are within the range delimited by the experimental onset and peak temperatures determined in

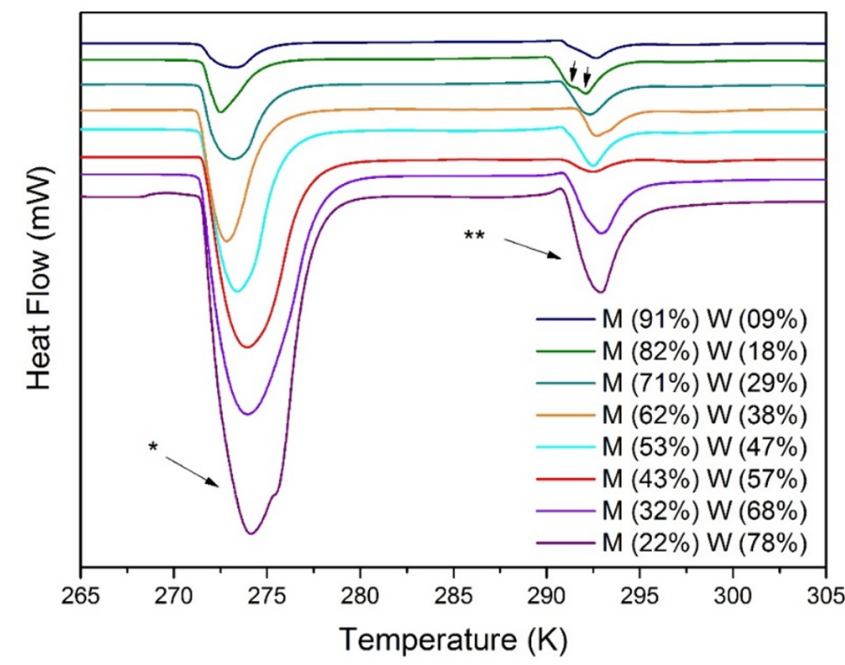

Figure 5. Ice melting $(*)$ and hydrate dissociation $(* *)$ peaks in the methane-water system at $21 \mathrm{MPa}$.

this work, the RMSD being $0.82 \mathrm{~K}$ and $0.80 \mathrm{~K}$ for the onset and peak temperatures, respectively. It means that there is no relevant difference between the use of onset or peak temperature for the binary system and the agreement observed demonstrates that the methodology is proper to determine the hydrate dissociation temperature. The absolute deviations between experimental data observed in this work and the predicted value using Multiflash are also consistent with those reported by Mohammadi et al. (2005), Jader and Sloan (2001), or Nixdorf and Oellrich (1997), although they were obtained with different methodologies.

Table 1. Peak temperatures of ice melting and hydrate dissociation of binary system formed by methane and water at $21 \mathrm{MPa}$.

\begin{tabular}{|c|c|c|c|c|c|c|c|c|c|}
\hline \multicolumn{2}{|c|}{$\begin{array}{l}\text { COMPOSITION } \\
\text { (Mole Fraction) }\end{array}$} & \multicolumn{4}{|c|}{ EXPERIMENTAL (HP- $\mu$ DSC) } & \multicolumn{2}{|c|}{ SIMULATION (Multiflash) } & \multirow{2}{*}{\multicolumn{2}{|c|}{$\begin{array}{c}\text { ABSOLUTE DEVIATION } \\
\left(\mathrm{T}_{\text {EXP. }}-\mathrm{T}_{\text {SIM. }}\right)\end{array}$}} \\
\hline \multirow[t]{2}{*}{$\mathrm{CH}_{4}$} & \multirow[t]{2}{*}{$\mathrm{H}_{2} \mathrm{O}$} & \multicolumn{2}{|c|}{$\begin{array}{c}T_{\text {ICE MELTING }} \\
(\mathrm{K})\end{array}$} & \multicolumn{2}{|c|}{$\begin{array}{l}T_{\text {HYDRATE DISS. }} \\
(\mathrm{K})\end{array}$} & \multirow{2}{*}{$\begin{array}{c}T_{\text {HYDRATE DISS. }} \\
(\mathrm{K})\end{array}$} & \multirow[t]{2}{*}{ Phases* } & & \\
\hline & & Onset & Peak & Onset & Peak & & & Onset & Peak \\
\hline 0.91 & 0.09 & 272.19 & 274.00 & 291.49 & 293.18 & 292.35 & G-W-S1 & -0.86 & 0.83 \\
\hline 0.82 & 0.18 & 272.30 & 273.26 & 290.91 & 292.64 & 292.35 & G-W-S1 & -1.44 & 0.29 \\
\hline 0.71 & 0.29 & 272.20 & 273.95 & 291.52 & 292.84 & 292.35 & G-W-S1 & -0.83 & 0.49 \\
\hline 0.62 & 0.38 & 272.11 & 273.58 & 292.35 & 293.22 & 292.35 & G-W-S1 & 0.00 & 0.87 \\
\hline 0.53 & 0.47 & 272.21 & 274.15 & 291.74 & 293.02 & 292.35 & G-W-S1 & -0.61 & 0.67 \\
\hline 0.43 & 0.57 & 272.38 & 274.67 & 291.56 & 293.01 & 292.35 & G-W-S1 & -0.79 & 0.66 \\
\hline 0.32 & 0.68 & 272.20 & 274.69 & 291.74 & 293.46 & 292.35 & G-W-S1 & -0.61 & 1.11 \\
\hline 0.22 & 0.78 & 272.28 & 274.88 & 291.66 & 293.44 & 292.35 & G-W-S1 & -0.69 & 1.09 \\
\hline \multicolumn{3}{|c|}{ REPORTED LITERATURE } & \multicolumn{4}{|c|}{ METHODOLOGY** } & SURE (MPa) & \multirow{2}{*}{\multicolumn{2}{|c|}{$\begin{array}{c}\mathrm{T}_{\text {HYDRATE DISS. }} \\
(\mathrm{K})\end{array}$}} \\
\hline \multirow{2}{*}{\multicolumn{3}{|c|}{ Mohammadi et al. (2005) }} & \multirow{2}{*}{\multicolumn{4}{|c|}{ Isochoric (pressure versus temperature plot) }} & 17.3 & & \\
\hline & & & & & & & 25.9 & \multicolumn{2}{|c|}{293.6} \\
\hline \multirow{2}{*}{\multicolumn{3}{|c|}{ Jader and Sloan (2001) }} & \multirow{2}{*}{\multicolumn{4}{|c|}{ Raman spectroscopy }} & 20.2 & \multicolumn{2}{|c|}{291.86} \\
\hline & & & & & & & 22.9 & & \\
\hline \multicolumn{3}{|c|}{ Nixdorf and Oellrich (1997) } & \multicolumn{4}{|c|}{ Isochoric (pressure versus temperature plot) } & 21.2 & \multicolumn{2}{|c|}{292.25} \\
\hline
\end{tabular}

* G: Gaseous phase; W: Liquid water; S1: Hydrate structure I.

** Methodology employed to determine hydrate equilibrium point. 
Considering the Gibbs phase rule, the binary system in a three-phase equilibrium state presents only one degree of freedom. Therefore, only one independent coordinate (pressure, temperature or composition) is required to define the thermodynamic state of the system. In this work, all experiments were carried out at the same pressure $(21 \mathrm{MPa})$, hence the temperature and the composition are already completely defined. Ergo given a specified pressure, the temperature at which the three phases coexist is also determined, independently of the composition. Nonetheless, the equilibrium of the system, even during a 10-min stabilization time after injecting gases, remains unassured and a gradient of methane concentration through the liquid phase due to the solubility variation with temperature might emerge. Therefore, experiments using the same procedure and different compositions were carried out to verify whether or not the hydrate dissociation temperature could vary significantly due to possible structural irregularities (e.g., empty cavities within the hydrate structure) caused by dynamic effects, considering a non-equilibrium state. As one can see in Table 1, our experimental results are very similar for all the studied compositions, which indicates that they correspond most probably to equilibrium states and the dynamic effects, if any, are negligible. The small root-mean square deviations observed $(0.8 \mathrm{~K})$ regarding simulations may be rather caused by systematic errors in the experiment itself.

In Figure 5 it is also possible to observe a larger melting ice curve with increasing amount of water inside the cell, which is reasonable since the heat measured by the scanning is an extensive quantity. Meanwhile, considering the low solubility of methane in water, no agitation within the cell and that the same pressure was maintained in all experiments, it was assumed that the formation of hydrate by crystallization in the system is limited by the area of the interface between the gas and the water (Figure 6). This interfacial area can change according to the disposition and size of water droplets and consequently with the amount of water in the system. However, these factors are irrelevant for the thermodynamic properties for the binary system and, consequently, the methodology presented in this work proves to be adequate to determine the hydrate dissociation temperature.

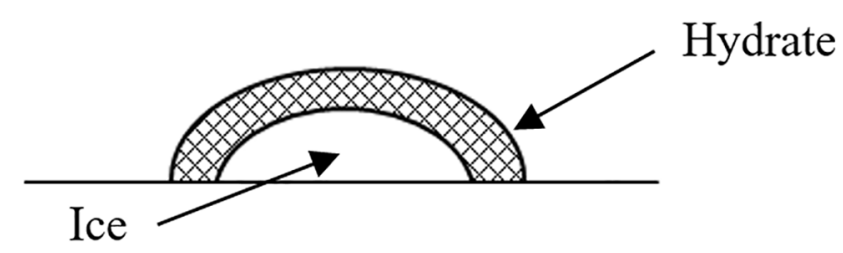

Figure 6. Schematic droplet representing a hydrate layer above ice core.

\section{Methane-propane-water System}

The ternary system composed of methane-propanewater was studied for different compositions to extend the existing experimental data in the literature using a methodology based on HP- $\mu$ DSC. For the ternary system in a three-phase equilibrium state, the number of degrees of freedom, according to the Gibbs phase rule, is two. Thus, for a given pressure and composition, the thermodynamic state of the system is completely defined. The hydrate dissociation temperature represents a transition between two regions in the phase diagram, going through an equilibrium line where three phases coexist: liquid hydrocarbon, liquid water with dissolved gas and hydrate (structure II), according to the simulations at the specified conditions.

Figure 7A shows the ternary diagram of this system obtained from the simulated data. The contour in the diagram represents the equilibrium temperature as a function of the system composition. The equilibrium temperatures for systems containing $10 \% \mathrm{~mol}$ of water are shown in Figure 7B. A maximum value for the equilibrium temperature is achieved when the methane mole fraction (excluding water) is about two thirds. This might be a result of the occupancy of cavities in the structure II. Larger guest molecules require bigger cages and typically determine the type of hydrate structure in mixtures (except for the mixture of methane and ethane) (Sloan and Koh, 2008). It is well known that propane tends to form structure II, but it only fits into large cavities of this structure $\left(5^{12} 6^{4}\right)$ and hence small cavities are only occupied by methane molecules $\left(5^{12}\right)$. Therefore, a higher temperature of dissociation is obtained when most of the large cavities are occupied by propane and most of the small ones by methane, which corresponds to the most thermodynamically stable configuration. In Figure 7B, this happens when the methane/propane ratio is about $2: 1$, which is in agreement with the proportion of small to large cavities in structure II (16:8, considering a unit cell). If the methane mole fraction (excluding water) is lower than $2 / 3$, more small cavities of structure II will be empty (since small cavities are unfit for propane molecules) and the dissociation of the hydrate is favored. In the opposite direction of the diagram, if the mole fraction of methane is higher, more of the large cavities will be occupied by methane instead of propane and the structure will require less energy to be dissociated (Subramanian et al., 2000).

Figure 8 shows thermograms related to the same ternary system. The onset and peak temperatures of ice melting and hydrate dissociation as well as simulation results by Multiflash 6.0 software and 

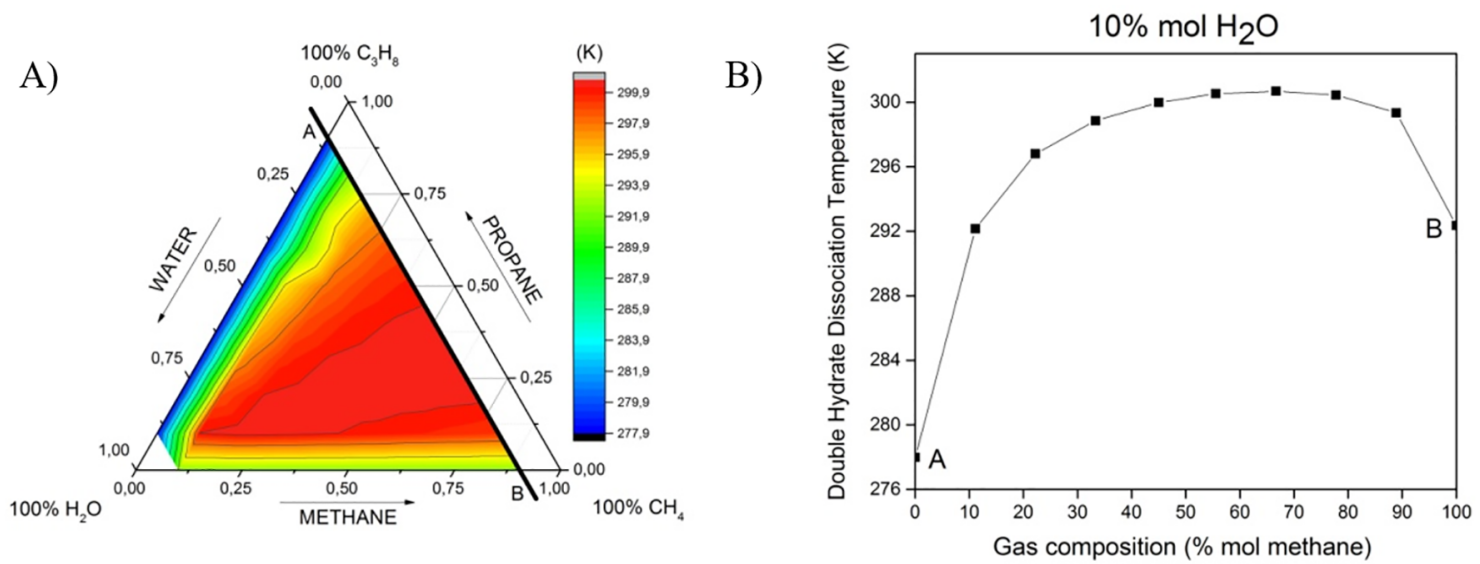

Figure 7. Ternary diagram of simulated hydrate dissociation temperatures vs composition in the system methane-propane-water at 21 $\mathrm{MPa}(\mathrm{A})$ and the temperature profile according to the propane-methane ratio in the section $\mathrm{AB}(\mathrm{B})$.

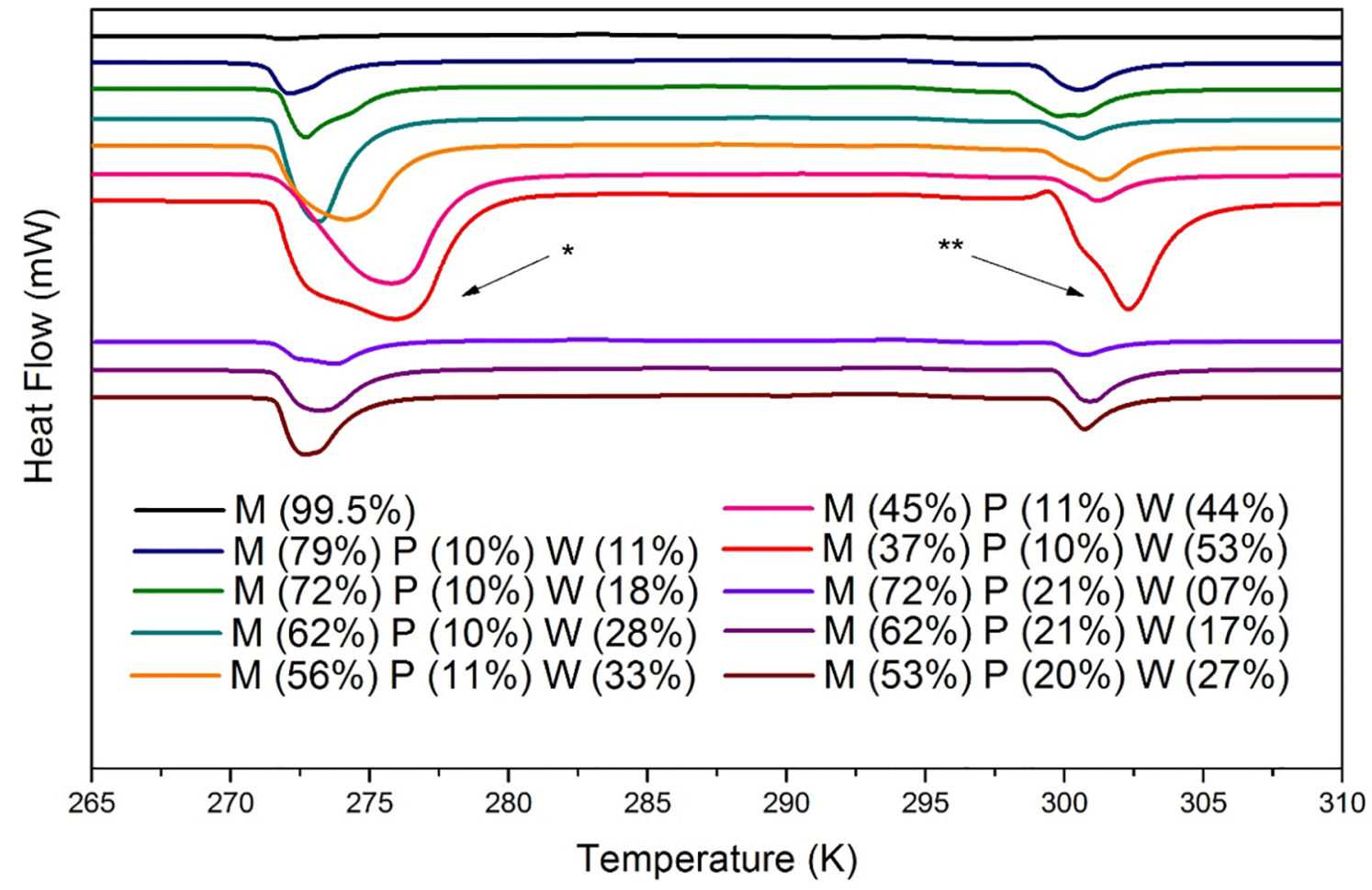

Figure 8. Ice melting $\left({ }^{*}\right)$ and hydrate dissociation $(* *)$ peaks in the methane-propane-water system at $21 \mathrm{MPa}$.

absolute deviations regarding simulated results are shown in Table 2. In most cases, predicted values are also within the range delimited by the experimental onset and peak temperatures determined in this work, the RMSD being $0.51 \mathrm{~K}$ and $1.34 \mathrm{~K}$ for the onset and peak temperatures, respectively. As can be observed, the RMSD from simulated results is higher for peak temperatures in this case. As previously stated, peak temperatures are more sensitive to mass variations. The higher the amount of sample, the higher the peak temperature. By observing Samples 6 and 7 from Table 2, it is possible to note the influence of the amount of water in the system on peak temperature, the onset temperature being practically unaffected. Both samples have the same water-free composition of gases, but the global composition indicates that sample 6 has $53 \%$ water, while sample 7 has only $7 \%$. Peak temperatures are, in this case, $302.72 \mathrm{~K}$ and 301.17 $\mathrm{K}$, respectively. However, onset temperatures are $300.17 \mathrm{~K}$ and $300.06 \mathrm{~K}$, respectively. In both cases, simulated results are about $300.4 \mathrm{~K}$, very close to the onset values.

Although for the binary system the dynamic effects were rather negligible and the RMSD for onset and peak temperatures regarding predicted values were similar, for the ternary system they must be taken into 


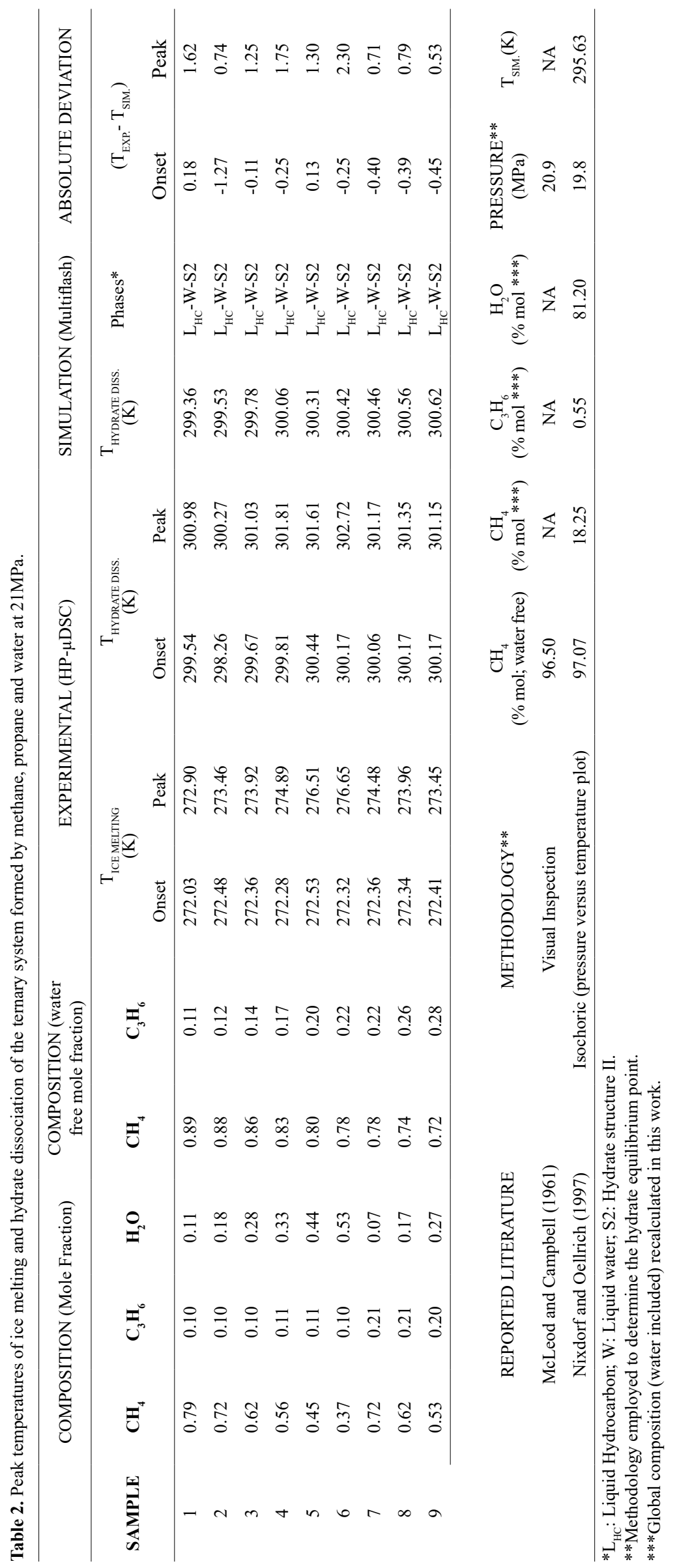


account. Since propane diffusivity in water is higher than methane diffusivity, inner regions of the hydrate film may be richer in propane and poorer in methane. The structure in this region may present emptier smaller cavities $\left(5^{12}\right)$, which should be occupied by molecules of methane. On the other hand, regions close to the surface could present most of the smaller cavities occupied by methane and hence a hydrate with higher occupation density. Taking this into account, a heterogeneous hydrate structure can be formed and it could influence the experimental dissociation temperature. Thermograms shown in Figure 8 presented more overlapped transitions for samples 1 , $2,3,4,5,6$, providing evidence of such heterogeneity in the ternary system. The results obtained for samples 7, 8 and 9 presented in Table 2 show lower absolute deviations for peak temperatures. Those samples contain the higher amounts of propane (water free composition) and water content between 7 and $27 \%$. Melting peaks observed for these mixtures in Figure 8 do not show overlapped transitions, which indicates more homogeneity.

Finally, the hydrate dissociation temperatures found in the literature for this ternary system were 296.56 $\mathrm{K}$ at 19.8 $\mathrm{MPa}$ (Nixdorf and Oellich, 1997) and 296.6 K at 20.9 MPa (McLeold and Campbell, 1961) using PVT cells by the isochoric method and visual inspection, respectively. However, global composition was not specified. McLeod and Campbell (1961) used a methane and propane mixture of $96.50 \%$ methane, while Nixdorf and Oellrich (1997) used $97.07 \mathrm{~mol} \%$ of methane for the same mixture, both are water-free composition. From the data published by Nixdorf and Oellrich (1997) the composition was recalculated by considering a water volume of $225 \mathrm{ml}$ and reactor volume of $500 \mathrm{ml}$, as specified by those authors, as well as an injection temperature of $294.15 \mathrm{~K}$. the PengRobinson EoS was also used to determine the gas density. Recalculated global compositions are shown in Table 2. In this case, the experimental dissociation temperature obtained by Nixdorf and Oellrich (1997) $(296.56 \mathrm{~K})$ is in a reasonable agreement with simulated results $(295.63 \mathrm{~K})$ provided by Mutiflash 6.0 for the recalculated global composition. The same calculation could not be done for compositions used by McLeod and Campbell (1961) because they did not specify either the amount of water used, or the reactor volume or the injection temperature. However, the experimental temperature obtained by those authors is very similar to the one obtained by Nixdorf and Oellrich (1997), which indicates that the global composition should be also comparable.

\section{CONCLUSIONS}

This work presents new experimental data for gas hydrate dissociation temperatures in mixtures of methane, propane and water at high pressure (21 $\mathrm{MPa})$. Such data were obtained using a high pressure differential scanning micro calorimeter. The PengRobinson EoS, which was proven to be reasonably accurate for the systems and conditions studied here, was used to compute the gas density inside the cell. For the binary system (methane+water), dynamic effects were found to be insignificant for the determination of the experimental hydrate dissociation temperature. $\mathrm{Au}$ contraire, the experimental results of the ternary system (methane+propane+water) have shown higher absolute deviations for peak temperatures from simulated values than the binary system, probably due to the formation of a heterogeneous hydrate caused by difference of methane and propane diffusivities in water. Even so, these results are undoubtedly relevant since, to the best of our knowledge, no experimental data were ever published for this ternary system under the same conditions as the ones investigated in this work.

\section{ACKNOWLEDGEMENTS}

The authors thank the financial support of FAPESP (processes 2014/02140-7, 2014/25740-0 and 2015/23148-9) and CNPq (process 132505/2015). The help of members of the laboratory GenBio (USP) is also gratefully acknowledged.

\section{REFERENCES}

Allison, E., Boswell, R., Methane Hydrate, Future energy within our grasp, DOE Overview. (2007). Document http://www.fossil.energy.gov/programs/ oilgas/hydrates/

Cha, M., Hu, Y., Sum, A.K., Methane hydrate phase equilibrium for systems containing $\mathrm{NaCl}, \mathrm{KCl}$, and $\mathrm{NH}_{4} \mathrm{Cl}$. Fluid Phase Equilibria, 413 2-9 (2016).

Chen, J., Sun, C.-Y., Liu, B., Peng, B.-Z., Wang, X.L., Chen, G.-J., Zuo, J. Y., Ng, H.-J., Metastable boundary conditions of water-in-oil emulsions in the hydrate formation region. AIChE J., 58: 22162225 (2012)

Dalmazzone, D., Hamed, N., Dalmazzone, C., DSC measurements and modelling of the kinetics of methane hydrate formation in water-in-oil emulsion. Chemical Engineering Science, 64(9) 2020-2026 (2009). 
Daraboina, N., Malmos C., Solms, N., Investigation of Kinetic Hydrate Inhibition Using a High Pressure Micro Differential Scanning Calorimeter. Energy Fuels, 27 5779-5786 (2013)

Deschamps, J., Dalmazzone, D., Dissociation enthalpies and phase equilibrium for TBAB semiclathrate hydrates of $\mathrm{N} 2, \mathrm{CO} 2, \mathrm{~N} 2+\mathrm{CO} 2$ and $\mathrm{CH} 4$ + CO2. J Therm Anal Calorim., 98 113-118 (2009)

Gao, G., A simple correlation to evaluate binary interaction parameters of the Peng-Robinson equation of state: binary light hydrocarbon systems. Fluid Phase Equilibria, 74 85-93 (1992).

Gupta, A., Lachance, J., Sloan, E. D., Koh, C.A., Measurements of methane hydrate heat of dissociation using high pressure differential scanning calorimetry. Chem. Eng. Sci., 63 5848-5853 (2008).

Ivanova, I.K., Semenov, M.E., Koryakina, V.V., Shits, E.Y., Rozhin, I. I, Investigation of natural gas hydrates formation/decomposition processes in systems consisting of "commercial asphalteneresin-paraffin deposits and water". Russian Journal of Applied Chemistry, 88 941-948 (2015).

Jager, M., Sloan, E., The effect of pressure on methane hydration in pure water and sodium chloride solutions. Fluid Phase Equilibria, 185 89-99 (2001).

Kim, H.C., Bisnoi, P.R., Heidemann, R.A., Rizvi, S.S.H., Kinetics of methane hydrate decomposition. Chemical Engineering Science, 42(7) 1645-1653 (1987).

Kouakou AC, Mapihan KL, Pauly J. Solid-liquid equilibria under high pressure of pure fatty acid methyl esters. Fuel 109 297-302 (2013).

Kvenvolden, K. A., Rogers, B. W., Gaia's breathglobal methane exhalations. Mar. Pet. Geol., 22 579-590 (2005).

Lee, J.D., Susilo, R., Englezos, P., Methane-ethane and methane-propane hydrate formation and decomposition on water droplets. Chemical Engineering Science, 60 4203-4212 (2005).

Linjun, W., Xuemin, Z., Honghui, L.I., Shao, L., Zhang, D., Jiao, L., Theory research on desalination of brackish water using gas hydrate method. Advaced Materials Research, 616-618, 1202-1207 (2013).

Makogan, Y. F, Hydrates of natural gas. PennWell Publishing: Tulsa, OK (1981).

McLeod, H. O. J., and Campbell, J. M., Natural Gas Hydrates at Pressures to 10,000 psia, J. Petl Tech, 222 590-594 (1961).

Mohammadi, A.H, Anderson, R., Tohidi, B., Carbon Monoxide Clathrate Hydrates: Equilibrium Data and Thermodynamic Modeling. AIChE Journal, 51 2825-2833 (2005).

Multiflash version 6.0.14, Infochem Computer Services Ltd / KBC Advanced Technologies, May 2015.
Nixdorf, J., Oellrich, L. R., Experimental determination of hydrate equilibrium conditions for pure gases, binary and ternary mixtures and natural gases. Fluid Phase Equilib., 139 325-333 (1997).

Ruffine, L., Donval, J.P., Charlou, J.L., Cremière, A., Zehnder, B.H., Experimental study of gas hydrate formation and destabilisation using a novel highpressure apparatus. Marine and Petroleum Geology, 27 1157-1165 (2010).

Sabil, K.M., Nashed,O., Lal, B., Ismail, L., JapperJaafar, A., Experimental investigation on the dissociation conditions of methane hydrate in the presence of imidazolium-based ionic liquids. The Journal of Chemical Thermodynamics, 84 7-13 (2015).

Sage, B. H., Lacey, W.N., Schaafsma, J. G., Phase Equilibria in Hydrocarbon Systems II. Methane - Propane System. Industrial and Engineering Chemistry, 26, 2 214-217 (1934).

Selim, M.S., Sloan, E.D., Heat and mass-transfer during the dissociation of hydrates in porous media. AIChE Journal, 35(6) 1049-1052 (1989).

Semenov, M.E, Manakov, A.Y., Shitz, E.Y., Stoporev, A.S., Altunina, L.K., Strelets, L.A., Misyura, S.Y., Nakoryakov, V.E., DSC and thermal imaging studies of methane hydrate formation and dissociation in water emulsions in crude oils. Journal of Thermal Analysis and Calorimetry, 119 757-767 (2015).

Setzmann, U., Wagner, W., A new equation of state and table of thermodynamics properties for methane covering the range from the melting line to $625 \mathrm{~K}$ at pressures up to $1000 \mathrm{MPa}$. The Journal of Physical Chemistry, 20 1061-1155 (1991).

Santos, L.C., Abunahman, S.S., Tavares, F.W., Ahón, V.R.R., Kontogeorgis, G.M., Cubic Plus Association Equation of State for Flow Assurance Projects. Industrial \& Engineering Chemistry Research, 54 6812-6824 (2015)

Sloan, E.D, Koh, C., Clathrate hydrates of natural gases, 3th edition, CRC Press, New York (2008).

Sloan, E., Koh, C., Sum, A., McMullen, N., Shoup, G., Ballard, A., Palermo, T., Creek, J., Eaton, M., Lachance, J., Talley, L., Natural gas hydrates in flow assurance. Elsevier, Burlington, MA (2011).

Subramanian, S., Kini, R.A., Dec, S.F., Sloan, E.D., Evidence of structure II hydrate formation from methane + ethane mixtures. Chemical Engineering Science, 55 1981-1999 (2000).

Ullerich, J.W., Selim, M.S., Sloan, E.D., Theory and measurement of hydrate dissociation. AIChE Journal, 33: 5, 747-752 (1987). 
Van der Waals, J. H., Platteeuw, J.C., Clathrate solutions, Advances in Chemical Physics, 2 1-57 (1959).

Vorotyntsev, V. M., Malyshev, V. M., Gas hydrates: nanosized phases in the separation and purification of substances by crystallization. Russian Chemical Reviews, 80(10) 971-991 (2011).
Xiang, C.S., Peng, B.Z., Liu, H., Sun, C.Y., Chen, G.J., Sun, B.J., Hydrate Formation/Dissociation in (Natural Gas + Water + Diesel Oil) Emulsion Systems. Energies, 6 1009-1022 (2013). 